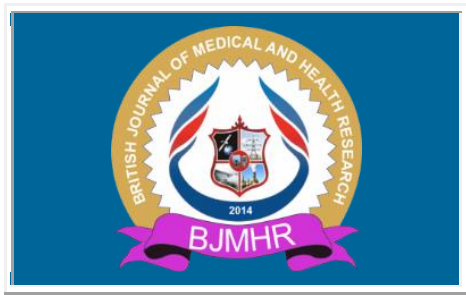

\title{
BJMHR
}

British Journal of Medical and Health Research

Journal home page: www.bjmhr.com

\section{Transportation and Rising Public Health Concerns In America}

Aneesh Sharma

2481 Poinciana Court, Weston, Florida, 33327

\section{ABSTRACT}

In the United States, countless public health issues disproportionately affect low-income and minority individuals - one being the obesity epidemic. Obesity is one of the leading causes of preventable deaths in the United States and is linked to a variety of serious health problems, including type 2 diabetes, high blood pressure, heart disease, stroke, some cancers, kidney disease, and more. One factor contributing to this racial health disparity is inadequate public and private transportation among such communities, making access to supermarkets (which carry fresh, healthy produce) less attainable. Solving the obesity epidemic in the United States will require significant government support and will likely take a combination of efforts to improve multiple factors in a community's food environment: corporate marketing, city zoning, supermarket pricing, transportation, etc. This review discusses the consequences - and potential solutions - of one aspect of the obesity epidemic: transportation. The focus of this paper is on the United States, but its content has international relevance relating to transportation's effects on public health as a whole.

Keywords: Obesity, Type 2 diabetes, Potential solutions, Transportation, Public health 


\section{INTRODUCTION}

Body Mass Index (BMI) is a metric used to quantify an individual's health and describe it using a single number. This popular metric is calculated by dividing weight $(\mathrm{kg})$ by height (meters) squared. An obese individual is defined as anyone with a BMI that is 30.0 or higher. As of 2018 , the CDC reported the US obesity rate to be $42.4 \%$ - substantially higher than most other countries.

Widespread obesity in the United States has several negative consequences. Most notably, obese individuals are at an increased risk for serious, potentially fatal health problems. Heart disease, kidney disease, and other life-threatening health issues are all more common in obese individuals than those at a healthy weight. Additionally, the United States will have to bear the economic implications of this increasingly worrisome issue. With each generation being more obese than the last, healthcare will cost the government more in the future than it ever has before.

Countless factors contribute to the rising obesity rates in the United States. One such factor is transportation. Owning personal transportation - such as cars and other motorized vehicles is expensive and difficult to maintain. Public transportation is rarely sufficient in most American cities. In fact, public transit systems are worse in low-income areas than most other areas. This makes grocery shopping difficult, and in theory, leads to more fast-food (and other unhealthy restaurant options) consumption among these individuals.

Due to these circumstances, low-income minorities experience higher rates of obesity than individuals of higher socioeconomic statuses. A study conducted in the early 2000's tested white and non-white participants of all ages and found that in almost all age groups tested, the Hispanic and Black participants were more likely to be overweight or obese than their white counterparts (Wang, Beydoun 2007). Similarly, the study found that high socioeconomic status individuals were less likely to be obese. Scholars have proposed many potential solutions to this problem including making improvements to public transportation in American cities.

This paper draws from existing literary reviews and primary research articles to identify and describe the current circumstances and flaws in public transportation systems in low-income and minority communities, also discussing how the issue can be fixed.

\section{Transportation}

One commonly suggested solution to the obesity epidemic is to solve the lack of transportation available to low-income communities. Building a grocery store in an underserved community - a commonly suggested solution to under consumption of fresh produce in certain communities - will not benefit its residents unless they have means of 
transportation to get to this newly built store. Many of these residents do not have access to a car as they are expensive to purchase, maintain, and consistently fill up with gas. Public transportation is also severely lacking in many of these neighborhoods. Additionally, walking to grocery stores can be difficult even if the store is somewhat nearby, since carrying several grocery bags across any distance is arduous and inconvenient (Byrne 2019). Some individuals, particularly women, forego walking to grocery stores for safety reasons, thus rendering trains and buses a potential solution.

It has been suggested that these trains and buses could even contain refrigerated storage for these grocery items. Online grocery shopping is an alternative solution. Numerous companies provide online grocery services such as "AmazonFresh," "Instacart," and "Fresh Direct." These websites allow users to shop for groceries online and then ship them to their doorstep. This system is extremely efficient for multiple reasons. Grocery store proximity would be less of an issue because customers would never have to leave their homes. Another added benefit would be that customers would spend much less time buying groceries online than in a supermarket. This is especially important for low-income families who do not have enough time to spend on lengthy grocery trips. There is, however, one major problem with this solution. Online grocery shopping is more expensive than in-person grocery shopping, often due to delivery charges, and is significantly more expensive than eating at fast-food restaurants.

\section{Analysis}

A priority of the public health field, and associated government officials, should be to make transportation more accessible to those who need it. Since many low-income individuals often work multiple jobs to support themselves financially, it is important for transportation to be time-efficient. This is why access to fast and reliable transportation is vital, particularly to travel to and from grocery stores. As previously mentioned in the paper, a refrigerated compartment in public transportation vehicles would provide individuals with assurance that their food will not spoil while returning home from the grocery store. This would make grocery shopping not only more efficient but also more accessible. Furthermore, the government should provide free transportation to those who live in small neighborhoods. This public transit system should be focused on providing all residents the ability to safely and efficiently get to the nearest grocery store.

Although it may not be very cost-effective for the government to provide transportation to small neighborhoods, particularly neighborhoods in a food desert, it is a sacrifice that must be made in order to help improve the overall health of the country. The United States has shown no sign of becoming a less obese nation and no improvements will be made unless drastic 
measures are taken. This largely neglected issue should be the government's top priority and should warrant extra government spending.

\section{CONCLUSION}

Obesity can no longer be ignored by politicians and American society as a whole. Not only is it a widespread health problem, but it disproportionately affects both people of color and impoverished individuals. Neglecting this issue would be a failure to our most vulnerable citizens. The mark of a truly great nation is not how it treats its wealthy, but how it treats its least fortunate. Despite having one of the largest economies in the history of mankind, the United States is one of the most obese countries in the world and fails to make an effort to keep its citizens healthy. This is, and has been for decades, one of the major faults of our nation. Nonetheless, there is a way to fix it. It will take a variety of unique approaches and will have to be largely supported by multiple levels of government. Fixing the transportation issues that the country has dealt with for decades would be a good place to start. Public transportation must have more of a focus on helping low-income individuals, especially those who live in food deserts. Solving an issue as big as the obesity epidemic in the United States is never going to be easy, but steps must be taken to ensure that future generations of Americans live long, healthy lives.

\section{REFERENCES}

1. "Adult Obesity Facts." Centers for Disease Control and Prevention, Centers for Disease Control And Prevention, 7 June 2021, www.cdc.gov/obesity/data/adult.html.

2. Byrne, Christine. "It's Great That We Talk About 'Food Deserts' - But It Might Be Time To Stop.” HuffPost. HuffPost, July 4, 2019. https://www.huffpost.com/entry/food-desert-problem-access-healthyoptions_n_5d1b910ee4b082e55370dee5?guccounter=1.

3. Ghosh-Dastidar, Bonnie. "Distance to Store, Food Prices, and Obesity in Urban Food Deserts.” NCBI. RAND Corporation, September 10, 2014. https://www.ncbi.nlm.nih.gov/pmc/articles/PMC4205193/.

4. Mulik, Kranti, and Lindsey Haynes-Maslow. “(PDF) A Community-Driven Approach to Generate Urban Policy" Science Direct, September 2017. https://www.researchgate.net/publication/324116798_A_CommunityDriven_Approach_to_Generate_Urban_Policy_Recommendations_for_Obesity_Prev ention.

5. Wang, Youfa, and May A. Beydoun. "Obesity Epidemic in the United States-Gender, Age, 
6. Socioeconomic, Racial/Ethnic, and Geographic Characteristics: A Systematic Review and Meta-Regression Analysis.” OUP Academic. Oxford University Press, May 17, 2007. https://academic.oup.com/epirev/article/29/1/6/440773.

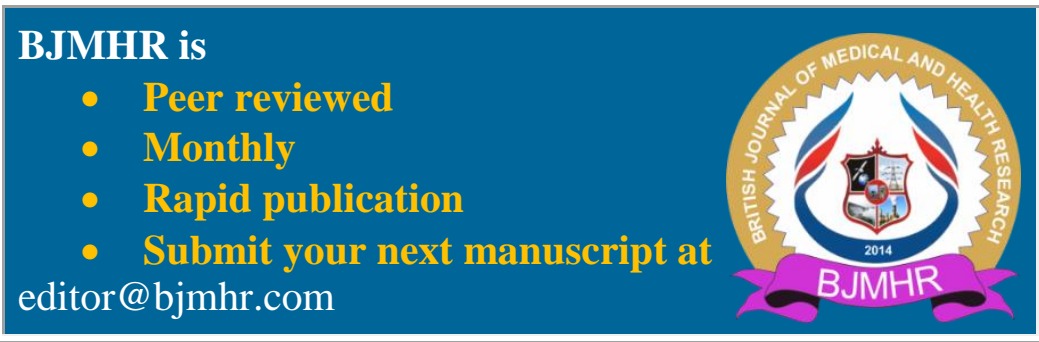

